\title{
Papers
}

\section{Mortality in young offenders: retrospective cohort study}

\author{
Carolyn Coffey, Friederike Veit, Rory Wolfe, Eileen Cini, George C Patton
}

\begin{abstract}
Objectives To estimate overall and cause specific standardised mortality ratios in young offenders. Design Comparison of mortality data in cohort of young offenders.

Settings State of Victoria, Australia.

Subjects Cohort of young offenders aged 10-20 years with a first custodial sentence from 1 January 1988 to 31 December 1999.
\end{abstract}

Main outcome measures Deaths ascertained by matching with the national death index, a database containing records of all deaths in Australia since 1980. Death rates in the reference Victorian population used to calculate standardised mortality ratios.

Results The offender cohort comprised 2621 men and 228 women with 11333 person years of observation. The median age of first detention was 17.9 years for men and 18.4 years for women. Median follow up was 3.3 years for men and 1.4 years for women. Overall standardised mortality ratio adjusted for age (expressed as a ratio) was 9.4 (95\% confidence interval 7.4 to 11.9 ) for men and 41.3 (20.2 to 84.7) for women. Cause specific standardised mortality ratios for men were 25.7 (17.9 to 36.9) for drug related causes, 9.2 (5.8 to 15) for suicide, and 5.7 (3.6 to 9.2) for non-intentional injury. A quarter of drug related deaths in men aged 15-19 years were in offenders.

Conclusions Social policies for young offenders should address both the prevalent drug and mental health problems as well the high levels of social disadvantage.

\section{Introduction}

Surveys have shown that socially disadvantaged and excluded young people have high levels of health problems, including psychiatric and behavioural disorders. ${ }^{1-3}$ To date there have been few studies of health related outcomes in young people in protective care, young offenders, and homeless young people. Reasons include difficulties in sampling and engagement and disrupted lifestyles that make tracing difficult. $^{45}$

The juvenile justice system, however, offers a potential framework for sampling and engagement. The health profile of young offenders is similar to that in other marginalised groups and marked by high rates of psychiatric disorder, ${ }^{5-8}$ childhood abuse, ${ }^{48}$ and, in recent decades, substance dependence. ${ }^{9-11}$ Studies of outcomes in antisocial and offending young people have suggested that death rates may be increased, ${ }^{12-14}$ but to date there seems to be no systematic report of mortality ratios in young offenders. We studied a 12 year cohort of young offenders sentenced to custody in Victoria, Australia, and linked data with the national death index to estimate both overall and cause specific mortality ratios.

\section{Methods}

\section{Study population: offender cohort}

We identified all adolescents known to have received their first custodial sentence in the state of Victoria, Australia, from 1 January 1988 to 31 December 1999. To ensure that the cohort consisted only of young people obtaining their first custodial sentence, we included only individuals who had been under 15 years on 1 January 1988-that is, under the minimum mandated age for detention at the start of the study. Follow up started on the date of first detention and ended with either death or censoring on 31 December 1999.

The offender cohort was identified through two data sources depending on age. Young offenders aged $10-16$ years were placed on statutory orders by the children's court for supervision by juvenile justice in the Victorian Department of Human Services. Before 1992, the minimum age at which a young person could receive a custodial sentence was 15 years. Younger children were assigned to custodial care and protection where no legal distinction was made between children needing protection and young offenders. On 22 April the legislation was amended to reduce the minimum age for detention from 15 years to 10 years; this was reflected in the minimum age for inclusion in the cohort.

In Victoria, a dual track custodial sentencing option was available so that offenders aged 17-20 years could serve their custodial sentence in either a juvenile justice centre or an adult prison, managed by adult corrections in the Victorian Department of Justice.

We obtained 2401 unique records for custodial offenders from juvenile justice and 740 from adult corrections. We excluded the two records in which the year of birth was entered incorrectly. We combined the two sets of records and identified the 290 duplicate records due to multiple sentences administered by both departments. To accord with contemporary statutory
Centre for

Adolescent Health, Murdoch Childrens Research Institute, Parkville, Victoria 3052, Australia Carolyn Coffey epidemiologist Friederike Veit paediatrician

Eileen Cini research assistant George C Patton professor director

Department of Epidemiology and Preventive

Medicine, Monash University,

Melbourne, Victoria 3000, Australia

Rory Wolfe

statistician

Correspondence to:

C Coffey

carolyn.coffey@

rch.org.au

bmj.com 2003;326:1064 
regulations, 30 individuals aged under 15 years who were recorded as being in custody before 22 April 1992 were deemed to enter the cohort on their 15th birthday ( $\mathrm{n}=28)$ or on 22 April $1992(\mathrm{n}=2)$, whichever occurred first.

The cohort consisted of 2849 young people (2625 male), minimum age 11 years. The median age at first detention for males was 17.9 (interquartile range 16.619.0) years and for females was 18.4 (interquartile range 16.7-19.4) years. The median follow up time was 3.3 years for males but only 1.4 years for females because $46 \%$ of males had entered the cohort by the end of 1995 whereas it took until 1997 for the same proportion of females to enter the cohort, reflecting different sentencing patterns.

The most serious offences recorded during follow up were violent crime (1544 males, 118 females); property crime $(815,73)$; drug only (possession, use, or trafficking or dealing in illicit substances, without charges for other crimes; 55, 7); and other offences $(172,29)$. For 39 no offence was recorded.

We obtained information on deaths by record linkage with the national death index, a database housed at the Australian Institute of Health and Welfare that contains records of all deaths in Australia since 1980. Records are obtained from the registrars of births, deaths, and marriages in each state and territory. Linkage was based on identifying information (surname, other names, alias names, sex, date of birth, date of last contact, postcode and state of residence, country of birth). Death registration number, date of death, age at death, state in which death occurred, and cause of death were provided for each match. Leading cause of

Table 1 Person years of observation (PYO) and selected causes of death in population of Victoria, Australia, and cohort of young offenders, 1988-99

\begin{tabular}{|c|c|c|c|c|c|}
\hline \multirow[b]{3}{*}{$\begin{array}{l}\text { Age group } \\
\text { (years) }\end{array}$} & \multirow[b]{3}{*}{ PYO } & \multicolumn{4}{|c|}{ No of deaths } \\
\hline & & \multirow[b]{2}{*}{ All cause } & \multicolumn{3}{|c|}{ Cause specific* } \\
\hline & & & Drug related & $\begin{array}{c}\text { Non-intentional } \\
\text { injury }\end{array}$ & Suicide \\
\hline \multicolumn{6}{|c|}{ Offender cohort } \\
\hline \multicolumn{6}{|l|}{ Male: } \\
\hline$\leq 14$ & 71.7 & 1 & 0 & 1 & 0 \\
\hline $15-19$ & 4840.7 & 33 & 16 & 9 & 6 \\
\hline $20-24$ & 5282.5 & 52 & 24 & 9 & 16 \\
\hline$\geq 25$ & 518.8 & 2 & 0 & 1 & 0 \\
\hline \multicolumn{6}{|l|}{ Female: } \\
\hline$\leq 14$ & 7.0 & 0 & 0 & 0 & 0 \\
\hline $15-19$ & 311.7 & 7 & 4 & 1 & 1 \\
\hline $20-24$ & 275.5 & 1 & 0 & 1 & 0 \\
\hline$\geq 25$ & 25.0 & 0 & 0 & 0 & 0 \\
\hline Total & 11333.0 & 96 & $44(46 \%)$ & $22(23 \%)$ & $23(24 \%)$ \\
\hline
\end{tabular}

Victorian population

\begin{tabular}{lccccc}
\hline Male: & & & & & \\
\hline$\leq 14$ & 670718 & 146 & 1 & 48 & 14 \\
\hline $15-19$ & 1667791 & 1080 & 69 & 477 & 236 \\
\hline $20-24$ & 873365 & 878 & 156 & 310 & 231 \\
\hline$\geq 25$ & 109413 & 131 & 38 & 29 & 40 \\
\hline Female: & & & & & 15 \\
\hline$\leq 14$ & 274589 & 51 & 1 & 143 & 4 \\
\hline $15-19$ & 1584927 & 428 & 33 & 84 & 57 \\
\hline $20-24$ & 845754 & 294 & 50 & 5 & 10 \\
\hline$\geq 25$ & 107117 & 43 & 8 & $1111(36 \%)$ & $662(22 \%)$ \\
\hline Total & 2812387 & 3051 & $356(12 \%)$ & &
\end{tabular}

${ }^{*}$ Cause specific grouping of deaths are mutually exclusive. Other causes of death in offender cohort (making up the $100 \%$ of all cause mortality) were: non-medical-homicide (one male, one female), legal intervention (one male); medical-diseases of circulatory system (one male), infectious and parasitic diseases (one male), neoplasms (one male), ill defined conditions (one male). death was coded by ICD-9 (international classification of disease, ninth revision) for deaths occurring before 1999 and by ICD-10 (international classification of disease, tenth revision) for 1999. The coroner for Victoria provided the leading cause of death for seven deaths identified by the national death index that lacked a cause. One death noted in the adult corrections database not identified by the national death index was confirmed by the coroner.

The Australian Bureau of Statistics provided the estimated resident population for the state of Victoria for each year, stratified by sex and age (year), and individual records identified from the Victorian mortality data unit, including sex, date of death, age at death, and leading cause of death (ICD-9 or ICD-10) for deaths registered between 1988 and 1999.

Codes including drug involvement were categorised as drug related. Non-intentional injury with drug involvement was classified only as "drug related" to establish mutually exclusive categories. Suicides resulting from overdose were classified as suicide, according to the coroner's assessment of intent.

\section{Data analysis}

Number of deaths and person years of observation were summed by year of age in the offender cohort. For the Victorian population, we calculated an average mortality for each year of age with averaging performed over those calendar years for which we had person years of observation in the offender cohort. In Victoria the population size by age varied little during the study period.

We calculated standardised mortality ratios ${ }^{15}$ with Stata 7 (StataCorp, College Station, TX, USA) and stratified by age into groups $(<15,15-19,20-24$, and $\geq 25$ years). We have reported all standardised mortality ratios as ratios rather than percentages. When we have referred to results from other publications we have converted their percentages to ratios for clarity.

In line with reports of increasing numbers of drug related deaths in young adults ${ }^{16}$ we observed that in Victoria rates for these deaths increased noticeably after 1997 in the 20-24 year age group. This increase was restricted to drug related deaths, was not apparent with other causes of death, and did not noticeably affect the overall death rates because of the relatively small contribution of drug related causes. For the estimation of drug related standardised mortality ratios therefore we stratified the Victorian rates by calendar year (before $1998 v 1998-9$ ) in the 20-24 year age group only.

We included deaths of offenders in states other than Victoria for calculations of standardised mortality ratios because we assumed a similar migration in the offender cohort and the general population.

\section{Results}

\section{Grude mortality}

Table 1 gives details of crude mortality in the cohort and general population. There were 96 deaths in the offender cohort: nine in custody, two on the day of release, six within 30 days of the last entered contact (for example, escaped, released on bail, not returned from court), four before the anticipated date of expiry 
Table 2 All cause mortality ratios by sex and age group and standardised mortality ratios by sex for cohort of young offenders, 1988-99

\begin{tabular}{lc} 
Age group (years) & Mortality ratio $(95 \% \mathbf{~ C l})$ \\
\hline Men: & \\
\hline$\leq 14$ & $71.0(1.7$ to 433.6$)$ \\
\hline $15-19$ & $9.7(6.3$ to 14.4$)$ \\
\hline $20-24$ & $9.7(7.0$ to 13.3$)$ \\
\hline$\geq 25$ & $3.2(0.4$ to 11.9$)$ \\
\hline Standardised & $9.4(7.4$ to 11.9$)$ \\
\hline Women: & $0(0.0$ to 3398.0$)$ \\
\hline$\leq 14$ & $81.0(30.8$ to 181.2$)$ \\
\hline $15-19$ & $10.4(0.3$ to 60.5$)$ \\
\hline $20-24$ & $0(0.0$ to 388.5$)$ \\
\hline$\geq 25$ & $41.3(20.2$ to 84.7$)$ \\
\hline Standardised
\end{tabular}

of the order, seven within 30 days after the anticipated date, and 68 more than 30 days after the anticipated date or last contact. These deaths resulted in a crude mortality of 8.5 deaths per 1000 person years of observation compared with $1.1 / 1000$ for the general population. The offender cohort contributed $12 \%$ of all drug related deaths in Victoria and 23\% of drug related deaths in 15-19 year old men. Most deaths in the Victorian population were due to non-intentional injury whereas in young offenders deaths from drug related causes predominated for both sexes.

\section{Standardised mortality ratios}

The risk of death was nine times higher in male offenders than in the reference Victorian male population (table 2). Although the estimate is unstable because of the small number of deaths, female offenders seemed to be about 40 times more likely to die than the reference Victorian female population.

We calculated cause specific standardised mortality ratios for men alone because the higher numbers of death permitted sensible estimation. The standardised mortality ratios were 26 (95\% confidence interval 17.9 to 36.9 ) for drug related deaths, 9.2 (5.8 to 14.7) for suicide, and 5.7 (3.6 to 9.2) for non-intentional injury.

\section{Discussion}

We included almost 3000 young offenders in this study, of whom 96 had died by the end of follow up. International comparison shows that overall death rates for young people in industrialised countries are broadly comparable. ${ }^{17}$ The crude mortality of 8.5/1000 person years of observation in the young offenders contrasts with mortality of 1.1/1000 for this age group in the reference population.

To provide a context for international comparison, the overnight detention rate in mid-1999 for sentenced men aged 15-20 years in Victoria was $14 / 10000$ relevant population in Victoria (derived from data used in this report) and was, for example, similar to 38/10 000 relevant population in England and Wales at the same time. ${ }^{18}$ For women the equivalent rates were 2/10 000 relevant population for both jurisdictions.

Comparison of standardised mortality ratios in the young offenders and other groups with high death rates further emphasises the importance of the findings. In people with a history of child and adolescent psychiatric treatment the standardised mortality ratio is 3.7 for all causes, 1.6 for schizophrenia, and 4.9 for anorexia nervosa. ${ }^{19}$ In similar age groups mortality ratios between 2 and 5 have been reported for recipients of child protection. ${ }^{20}$ Excess mortality during adolescence in young people receiving treatment for substance dependence, recently estimated as 11 in men and 21 in women, ${ }^{21}$ seems comparable with our overall estimates of 9 and about 40, respectively, and is consistent with the important role of drug misuse both in offending ${ }^{9}$ and in subsequent mortality. That the standardised mortality ratio for males for drug related causes was 26 further emphasises the importance of substance misuse in our cohort.

\section{Limitations}

Potential study limitations include a possibility of incorrect ascertainment of death due to incorrect or missed matches. The number of medium probability matches provided by the national death index was small, and we rejected them all after consideration of identifying data, making it unlikely that we overcounted deaths among offenders. One death noted in the justice data was not identified by the national death index, raising the possibility that we may have missed some offender deaths. The process of death notification results in a short time lag in availability of data from the national death index and the Australian Bureau of Statistics. With such large standardised mortality ratios, however, these possible minor ascertainment errors should not affect interpretation of the results. A further consideration is the possibility of misclassification of accidental death and drug overdoses as suicide, but it is unlikely that systematic classification bias has affected the outcomes.

\section{Conclusions}

The finding that death rates in young offenders exceed those in groups with even higher rates of psychiatric and behavioural disorders indicates that social disadvantage and marginalisation of this group may

What is already known on this topic

Socially excluded young people experience high levels of psychiatric disorder, childhood abuse, and substance dependence

Death rates in antisocial and offending young people are high

\section{What this study adds}

Young male offenders were nine times more likely and female offenders were 40 times more likely to die than young people in the general population

Drug related causes, suicide, and non-intentional injury were the leading causes of death

Mortality in young offenders was higher than in equivalent age groups with schizophrenia or eating disorders

Young offenders accounted for a quarter of drug related deaths in 15-19 year old men 
have played an additional part in many of the deaths. The findings have important implications for social policies for young offenders. On one hand the high rates of deaths due to drug overdose and suicide indicate a need for a better response to prevalent problems of drug misuse and psychiatric disorder. On the other hand, we also need to develop strategies effective in the social reintegration of young offenders. Education and training, accommodation, and family interventions will probably play an important part. ${ }^{22}$ Health practitioners are likely to have an essential role in the implementation of such responses.

Contributors: CC contributed to the conception, design, analysis, interpretation of the data, and drafted the manuscript. FV contributed to the conception, interpretation of data, and manuscript preparation. RW contributed to the design, analysis, interpretation of data, and manuscript preparation. EC was the data manager and contributed to the analysis and to manuscript preparation. GP contributed to the conception, design, analysis, data interpretation, and revised the manuscript critically for important intellectual content. All authors gave final approval of the version to be published. In addition, Lyndsey Watson from La Trobe University, assisted with the analysis. CC is the guarantor.

Funding: National Health and Medical Research Council Competing Standard Project Grant 105422. The guarantor accepts full responsibility for the conduct of the study, had access to the data, and controlled the decision to publish.

Competing interests: None declared.

Ethical approval: Ethics committees of the Royal Children's Hospital, Victorian Departments of Human Services and Justice, and the Australian Institute of Health and Welfare.

1 Farrington DP. Crime and physical health: illness, injuries, accidents and offending in the Cambridge study Crim Beh Ment Health 1995:5:261-78. Weinberg NZ, Rahdert E, Colliver JD, Glantz MD. Adolescent substance abuse: a review of the past 10 years. J Am Acad Child Adolesc Psychiatry 1998;37:252-6

3 Thompson SC, Ogilvie E, Veit F, Crofts N. Serostatus for vaccinepreventable diseases in residents at Melbourne Juvenile Justice Centre Aust N Z J Public Health 1998;22:573-7.
4 Silbereisen RK, Robins L, Rutter M. Secular trend in substance use: concepts and data on the impact of social change on alcohol and drug abuse In: Rutter M, Smith DJ, eds. Psychosocial disorders in young people, ChichesIn: Rutter M, Smith D

5 Kosky RJ, Sawyer MG, Fotheringham M. The mental health status of adolescents released from custody: a preliminary study. Austr N Z J Psychiatry 1996;30:326-31

6 Bickel R, Campbell A. Mental health of adolescents in custody: the use of the "adolescent psychopathology scale" in a Tasmanian context. Austr N Z J Psychiatry 2002;36:603-9

7 Fasher AM, Dunbar N, Rothenbury BA, Bebb DK, Young SJ. The health of a group of young Australians in a New South Wales juvenile justice detention centre: a pilot study. J Paediatr Child Health 1997;33:426-9.

8 Kosky RJ, Sawyer MG, Gowland JC. Adolescents in custody: hidden psychological morbidity? Med J Austr 1990;153:24-7.

9 Thompson SC, Ogilvie EL, Veit FC, Crofts N. Juvenile offenders and hepatitis B: risk, vaccine uptake and vaccination status. Med J Austr 1998;169:306-9.

10 Veit F. Ethical issues in harm reduction for adolescent illicit drug users: the adolescent forensic health service approach. Drug Alcohol Rev 2000;19:457-67.

11 Smith DJ. Youth crime and conduct: trends, patterns and causal explanations. In: Rutter M, Smith DJ, eds. Psychosocial disorders in young people. Chichester:John Wiley, 1995.

12 Stattin H, Romelsjo A. Adult mortality in the light of criminality, substance abuse, and behavioural and family-risk factors in adolescence. Substance abuse, and behavioural and fan

13 Yaeger CA, Lewis DO. Mortality in a group of formerly incarcerated juvenile delinquents. Am J Psychiatry 1990;147:612-4.

14 Rydelius PA. The development of antisocial behaviour and sudden violent death. Acta Psychiatr Scand 1988;77:398-403.

15 Rothman KJ, Greenland S. Modern epidemiology. Philadelphia: LippincottRaven, 1998.

16 Hall W, Degenhardt L, Lynskey M. Trends in opioid overdose and suicide mortality in young adults in Australia 1964-97. Sydney, NSW: University of New South Wales, 1999. (NDARC Technical Report No 67.)

17 Leffert N, Petersen AC. Patterns of development during adolescence. In: Rutter M, Smith DJ, eds. Psychosocial disorder in young people. Chichester: Jutter M, Smith DJ, eds.

18 StatBase National Statistics data and references. wwwstatistics.gov.uk statbase/ (Accessed may 2002).

19 Harris EC, Barraclough B. Excess mortality of mental disorder. Br J Psychiatry 1998;173:11-53.

20 Kalland M, Pensola TH, Merilainen J, Sinkkonen J. Mortality in children registered in the Finnish child welfare registry: population based study. BMJ 2001;323:207-8.

21 Oyefeso A, Ghodse H, Clancy C, Corkery J, Goldfinch R. Drug abuse-related mortality: a study of teenage addicts over a 20 -year period. Soc Psychiatry Psychiatr Epidemiol 1999:34:437-41.

22 Anderson B, Beinhart P, Farrington D, Longman J, Sturgis P, Utting D. Risk and protective factors associated with youth crime and effective interventions to prevent it. London: Youth Justice Board, 2001. (Research Note No 5.) (Accepted 6 March 2003) 